\title{
O Novo Ensino Médio e a Língua Inglesa: uma análise sobre o ensino de oralidade em um material didático sob a perspectiva do inglês como língua franca
}

\author{
The New High School and the English Language: an analysis of the \\ teaching of orality in a didactic material from the perspective of English \\ as a lingua franca
}

Matheus Aniecevski

Taisa Pinetti Passoni²

\begin{abstract}
Resumo
O presente artigo visa a apresentar um panorama de alguns estudos que relacionam as proposições da Base Nacional Comum Curricular (BNCC) e do Novo Ensino Médio (NEM), tendo em vista o ensino de Língua Inglesa sob a perspectiva do Inglês como língua franca (ILF). Para situar a discussão, este trabalho propõe-se a analisar atividades de oralidade em duas unidades didáticas de dois livros distintos: o primeiro, com edição de 2016, ainda voltado aos moldes já consolidados do Ensino Médio; e o segundo, com edição de 2020, já adequado ao NEM. A análise comparativa dos dois materiais evidencia as mudanças que já começam a ser estabelecidas no processo de ensino de oralidade de inglês, tanto no formato do material didático quanto na elaboração das atividades.
\end{abstract}

Palavras-chave: BNCC. Novo Ensino Médio. Língua Inglesa.

\begin{abstract}
This article presents an overview of the studies that relate the propositions of the National Common Curricular Base (BNCC) and New High School (NEM) aiming to teach English in the perspective of English as a lingua franca (ILF). To situate the discussion, this paper proposes to analyze oral activities in two teaching units of two different coursebooks: the first, published 2016, still focused on the already consolidated models of High School; and the second, published in 2020, already adapted to the NEM. The comparative analysis of the two materials shows the changes that are already beginning to be established in the English language oral teaching process, both in the format of the didactic material and in the elaboration of the activities.
\end{abstract}

Keywords: BNCC. New High School. English Language.

1 Introdução

O caso da reforma trazida pelo Novo Ensino Médio (NEM), proposto pelo governo federal em 2017, coloca-se como uma tentativa, por parte das esferas gestoras do sistema educacional brasileiro, de proporcionar aos estudantes uma formação integral que permita uma participação social mais efetiva. Desde 2018, quando a última versão da Base Nacional Comum Curricular (BNCC) foi lançada, o governo federal instituiu que, até 2022, todas as escolas do país deverão contemplar o NEM.

\footnotetext{
1 Mestrando em Letras. Universidade Tecnológica Federal do Paraná, Pato Branco, Paraná, Brasil. Orcid: https://orcid.org/0000-0003-2456-257X/ E-mail: Matheus_aniecevski@hotmail.com.

2 Doutora em Estudos da Linguagem. Universidade Tecnológica Federal do Paraná, Pato Branco, Paraná, Brasil. Orcid: http://orcid.org/0000-0001-7819-1327/ E-mail: taisapassoni@utfpr.edu.br.
}

LínguaTec, Instituto Federal de Educação, Ciência e Tecnologia do Rio Grande do Sul, Bento Gonçalves 
Com a implementação do NEM, além do aumento de carga horária para os estudantes, passando de 800 para 1000 horas anuais, a política traz consigo uma série de mudanças para o ensino, incluindo a BNCC como documento norteador que garante uma série de habilidades e competências a serem desenvolvidas pelos educandos ao final da Educação Básica.

No caso específico da Língua Inglesa (LI) como componente curricular, a principal mudança é o tratamento recebido na Base, sendo agora denominada como uma língua franca, definido por Jenkins (2009) como uma língua de contato e comunicação entre dois falantes cuja primeira língua se diferem. Segundo a Base, "a língua inglesa não é mais aquela do 'estrangeiro', oriundo de países hegemônicos, cujos falantes servem de modelo a ser seguido, nem tampouco trata-se de uma variante da língua inglesa" (BRASIL, 2018, p. 241). Tais mudanças, sejam na perspectiva do Inglês como Língua Franca (ILF) ou no formato do NEM, podem ser interpretadas como uma tentativa de suprir algumas das lacunas que emergem na história da educação.

As Leis de Diretrizes e Bases da educação (LDB) № 9.394/96, no que tange ao EM, previa apenas a oferta de uma língua estrangeira (LE) moderna como disciplina obrigatória, a qual seria escolhida pela comunidade escolar, e em caráter optativo, uma segunda língua dentro das disponibilidades da instituição. Algum tempo depois, os Parâmetros Curriculares Nacionais (PCNs) (BRASIL, 2000), começam a traçar os primeiros passos para refletir sobre o ensino de LI.

Ao abordar a inclusão da LE no currículo, esses parâmetros afirmam que o domínio linguístico requer "competência interativa, que se desenvolve por meio do uso da linguagem em situações de diálogo entre falantes que partilham o mesmo idioma, pautadas por regras comuns e reciprocamente convencionadas" (BRASIL, 2000, p. 96). Ou seja, a comunicação enfatizada, nesse primeiro momento, trata apenas da comunicação entre falantes que possuem um mesmo idioma em comum. É somente com a Lei $n^{0}$ 13.415/2017, que o Inglês ganha sua efetivação e se torna obrigatório desde $06^{\circ}$ ano do Ensino Fundamental (EF) até o EM, o que, por consequência, impactou a construção das novas orientações curriculares propostas pela BNCC.

Segundo a BNCC (BRASIL, 2018), documento mais atual referente à organização curricular da Educação Básica, abordar a LI como componente curricular significa "abrir possibilidades de aproximação e integração dos estudantes com grupos multilíngues e multiculturais no mundo globalizado no qual a língua inglesa se apresenta como língua comum para interação" (BRASIL, 2018, p. 484). Compreender esse processo de construção de um espaço para LI no currículo da escola é importante para refletir sobre as lacunas deixadas ao longo dos anos nesse processo de ensino.

Embora essas questões em torno da permanência, da obrigatoriedade e do ensino propriamente dito da LI nas escolas públicas sejam alvos de discussões ao longo dos anos, a proposição do NEM e 
todas as mudanças que ele acarreta ainda são muito recentes. Considerando que o prazo que as escolas têm para implementá-lo seja 2022, algumas instituições do país já atuam como piloto ${ }^{3}$ e começam a receber as primeiras orientações e os primeiros materiais didáticos organizados conforme propõe a BNCC.

Com essa contextualização apresentada, o presente artigo visa discorrer acerca de um panorama sobre alguns estudos que já começaram a ser desenvolvidos na área do NEM e da LI, observar o percurso da definição do ILF proposto pelos teóricos e analisar duas unidades didáticas de dois materiais distintos tratando da perspectiva do ILE e do ILF. Para tanto, primeiramente apresentamos um panorama sobre os estudos do NEM e a LI. Na seção seguinte, discutiremos a perspectiva do ILF seguindo o ensino de oralidade em LI. Após, apresentamos a metodologia e a análise das unidades com consequentes considerações finais e resultados obtidos.

\section{Novo Ensino Médio e a Língua Inglesa}

Para reconhecer o cenário atual das pesquisas sobre o tema, foi realizada, no mês de abril de 2021, por meio do Google Scholar, uma busca com os termos "BNCC", "Novo Ensino Médio" e "Língua Inglesa". Restringimos a busca com base na data da última versão da BNCC, ou seja, de 2018 até o presente momento. Obtivemos em torno de 427 resultados na busca ${ }^{4}$, com 10 artigos publicados por página. Os estudos a seguir citados são os cinco primeiros resultados da primeira página da web, sendo representados pelo próprio mecanismo de pesquisa como "os mais relevantes e/ou mais citados".

Pfeiffer e Grigoletto (2018) abordam a textualidade da reforma do EM e as relações interdiscursivas e intertextuais do texto da lei que institui a reforma. As autoras concluem que a implementação da Base e consequente reforma são, na verdade, formas de tentar tornar o currículo mais atrativo, porque afinal de contas, os jovens, em especial os mais pobres da escola pública, precisam estar inseridos no sistema educacional.

Além disso, afirmam que, para esses alunos, não faz sentido o que a escola ensina, pois está em desalinho com o desejo de muitos desses jovens: o mundo do trabalho, e assim discorrem sobre essa formação ideológica e neoliberal. Assim, salientam que esse jovem vai fazer as escolhas (itinerários

\footnotetext{
${ }^{3}$ Escolas-Piloto para o NEM: <https://www.in.gov.br/materia/-/asset_publisher/Kuirw0TZC2Mb/content/id/29495231/dol-201807-11-portaria-n-649-de-10-de-julho-de-2018-29495216> e <https://www.gov.br/mec/pt-br/novo-ensino-medio/programa-deapoio-ao-novo-ensino-medio>. Acesso em: 23 de out. 2021.

${ }^{4}$ Esses 427 resultados apresentados tratam de diferentes produções acadêmicas, mas como delimitação deste trabalho, contextualizamos os 5 primeiros artigos apresentados como os mais relevantes pelo próprio navegador.
} 
formativos) durante o percurso do NEM condizentes com o "mínimo e necessário para atender ao mercado de trabalho" (PFEIFFER; GRIGOLETTO, 2018, p. 22).

Nesse viés, o estudo de Ferreira e Ramos (2018) também comenta a decisão arriscada de se permitir que os estudantes possam optar pelos seus itinerários formativos ao longo do EM. Para as autoras, isso requer da escola uma estrutura que atualmente será muito desafiadora. Tais estudos foram de substancial importância, pois os desafios apontados pelas autoras no estudo tratam, sobretudo, do investimento financeiro necessário para que a implementação ocorra de modo efetivo na formação desse aluno.

Silva e Boutin (2018), ao abordarem os conceitos e as polêmicas do NEM, estabelecem reflexões claras de que a formação integral, proposta pelo Programa, servirá a uma formação mais técnica que rege a ideia do jogo de interesses do capital. É perceptível, nesse caso, que após o termo "formação integral" aparecer na BNCC (2018), estudiosos como Silva e Boutin (2018) se propuseram a estudá-lo, e, para tanto, há nos resultados obtidos pelos autores essa preocupação que, segundo eles, no NEM se tornou menos propedêutica.

Em sua pesquisa, Süssekind (2019) define a reforma como arrogante, indolente e malévola ao criticar a unificação do currículo por meio da BNCC para todo o território nacional como sendo uma produção epistemicida. Para a autora, essa unificação de um currículo em visão nacional pode levar ao apagamento das diferenças e também tratar os professores como meros reprodutores, pois também visa unificar essa prática docente transformando o currículo em algo imposto e não construído dialogicamente.

A investigação de Costa e Silva (2019) analisa a proposta do NEM sob a ótica de entidades acadêmicas da área educacional baseados nos conceitos de democracia no contexto do neoliberalismo, direito à educação e conhecimento mais amplo da juventude e medidas que acenam para a privatização da educação. Para os autores, essas reformas caminham no sentido de precarizar o direito à educação em vez de garantir sua efetivação e sua ampliação (COSTA; SILVA, 2019, p. 20). Discussões como essa, apontam que a BNCC precisa ser repensada antes da sua efetivação, afinal de contas, as discussões relatam professores sem formação continuada para lidar com o documento, e sinalizam para ideia ilusória de produzir um único documento norteador para o país todo. Além disso, os estudos nos mostram a necessidade de uma leitura mais crítica do documento, buscando compreender os interesses envolvidos na implementação da Base.

Quando partimos para uma análise mais específica do componente curricular de Ll e sua posição no NEM, os estudos aparecem em número reduzido e ainda não tão explorados. Na busca pelo Google 
Scholar, ao acrescentarmos o termo "língua inglesa", encontramos 102 resultados 5 , o que já indica um número menor em relação à primeira busca mais ampla apresentada inicialmente. Abaixo são selecionados cinco estudos como resultados da primeira página da busca, apontados também pelo próprio navegador como "os mais relevantes e/ou mais citados".

Dentre as publicações específicas da área de LI encontradas, temos acesso ao estudo de Farias e Silva (2020), os quais se detiveram em analisar a LI na BNCC em contraste com a pedagogia crítica proposta por Paulo Freire. Contudo, a análise é pautada apenas no EF. Para os autores, a BNCC apresenta uma visão crítica do papel da LI, porém não problematiza verdadeiramente como fazê-lo. Além disso, os autores identificaram um apagamento dos problemas sociais, que não são apresentados como objetos de estudos da unidade curricular.

Já Santana e Kupske (2020) analisam o paradoxo da mudança de ILE para o ILF proposto pela Base. Segundo os autores, a mudança em um primeiro momento acontece apenas no documento, tal movimento não se manifesta na escola, afinal de contas, os contextos e condições de ensino de inglês continuam sendo os mesmos, com o mesmo número de aulas semanais e, até então, com os mesmos materiais didáticos. Além disso, os autores salientam outro ponto: a necessidade de formação inicial e continuada dos professores de LI.

$\mathrm{Na}$ terceira pesquisa encontrada, com foco em um estudo de caso com professores de LI, também do EF, da rede pública de ensino, Amorim e Gomes (2020) constataram que há muitas dificuldades a serem enfrentadas pelos docentes para implementação dos conceitos propostos pela Base, pois, para os autores, há muitos conceitos modernos sobre ensino-aprendizagem de LE na Base, o que necessitará de uma formação inicial e continuada aos docentes.

Já Alves e Siqueira (2020) também abordam a questão da língua franca como agente de decolonialidade no ensino da LI, estudando e analisando o ensino do idioma e o enfrentamento das forças coloniais que continuam reverberando nas aulas de inglês. Ainda nesse viés, o estudo de Marson (2021) desenvolve uma possível discussão entre o ensino de LI no Brasil e a Decolonialidade. A autora salienta que, por meio de análise documental, a BNCC apoia o ensino do ILF, entretanto, enfatiza a colonialidade pela unicidade da língua como obrigatória.

Os estudos citados foram desenvolvidos, em sua maioria, por professores de universidades públicas do país, alguns deles por doutorandos e mestrandos. 0 que é perceptível é que tanto a implementação do NEM quanto o ensino da LI nesse contexto são muito recentes e as discussões

\footnotetext{
${ }^{5}$ Novamente, os 102 resultados encontrados tratam de diferentes produções acadêmicas, contudo a delimitação atribuída a esse estudo é aos 5 primeiros artigos acadêmicos encontrados na primeira página da web.
} 
incipientes, com base nos estudos de relatos dos professores, apontam para a necessidade de formação inicial e continuada de docentes. Entretanto, as publicações encontradas discorrem acerca do contexto do EF. Assim, os estudos parecem revelar justamente as lacunas existentes tanto na BNCC quanto no NEM no que tange às especificidades do ensino do idioma nesta nova realidade. Ou seja, tendo em vista que as orientações da Base para EF, relativas ao componente de LI, são razoavelmente detalhadas e que se pressupõe que o EM seja a continuidade e 0 aprofundamento dos estudos iniciados na etapa anterior, é quase que um processo intuitivo recorrer às considerações relativas ao EF na busca pela compreensão dos desdobramentos esperados para a etapa seguinte.

Ao mesmo tempo, podemos também compreender que a carência por orientações específicas para o EM podem constituir desafios para os docentes encarregados de implementar esta nova política em sala de aula. Como forma de tentar sanar essas lacunas, algumas formações continuadas já foram desenvolvidas nas escolas piloto do NEM, como por exemplo, a formação fornecida aos docentes pela Secretaria do Estado de Educação de Santa Catarina (SED-SC). As formações visavam a situar os professores acerca dos novos termos propostos pela BNCC, como por exemplo, desenvolvimento de habilidades e competências, avaliação formativa, áreas de conhecimento, itinerários formativos, componentes eletivos etc.

A primeira parte da formaçãa $0^{6}$ foi realizada de forma presencial, no início de 2020, e objetivava situar os professores sobre todos os novos conceitos que o NEM trazia consigo. A formação contou com uma carga horária de 40 horas na semana anterior ao início das aulas. A segunda ${ }^{7}$ e terceira ${ }^{8}$ partes da formação também contemplavam 40 horas, contudo, ofertadas de forma remota aos professores no segundo semestre do ano letivo de 2020 devido à pandemia da Covid-19. Nessa etapa, algumas experiências foram socializadas com 0 trabalho com o NEM nas escolas piloto (ainda que de forma remota), além de formações mais específicas a cada professor com os organizadores curriculares de cada componente curricular nas etapas de EF e EM. Sendo assim, com base nos resultados obtidos na pesquisa do Google Scholar, salientamos que a falta de infraestrutura e a formação continuada aos docentes para lidar com os novos conceitos expostos pela Base aparecem como pontos principais para a continuidade de estudos nessa área.

\footnotetext{
6 Disponível em: http://extranet.sed.sc.gov.br/index.php/downloads/digr/formacao-continuada-de-professores-da-educacaobasica-descentralizada-fevereiro-de-2020/materiais-para-a-formacao/ensino-medio. Acesso em: 08/06/2021. 7 Disponível em: https://sites.google.com/sed.sc.gov.br/scemformacao/1\%C2\%BA-ciclo-de forma $\%$ C3\%A7\%C3\%A3o/forma\%C3\%A7\%C3\%B5es-1\%C2\%BA-ciclo?authuser=0. Acesso em: 08/06/2021. 8 Disponível em https://sites.google.com/sed.sc.gov.br/scemformacao/1\%C2\%BA-ciclo-deforma $\%$ C3\%A7\%C3\%A3o/forma\%C3\%A7\%C3\%B5es-1\%C2\%BA-ciclo?authuser=0. Acesso em: 08/06/2021.
} 


\section{Inglês como língua franca}

Os estudos do ILF, concebida como língua de contato e comunicação entre dois falantes cuja primeira língua se diferem (JENKINS, 2009), também são recentes no país, embora as publicações sejam anteriores à reforma do NEM. Nesse sentido, Salles e Gimenez (2013), em um artigo sobre a formação de professores de inglês para o contexto de língua franca, já ressaltavam que os estudos sobre tal perspectiva eram inaugurais aqui no Brasil, contudo tomando como subsídio os estudos internacionais sobre o tema.

Duboc (2019) afirma que as pesquisas sobre o ILF datam a década de 1980, quando os trabalhos pioneiros de Jenkins (2000) e Seidlhofer (2001) começaram a questionar a real utilidade do modelo do falante nativo perante às normas de uso do inglês nos mais diversos contextos multilíngues. Assim, Jenkins (1980) é uma das autoras pioneiras nos estudos desenvolvidos na perspectiva do ILF, e que tem retratado o processo de recontextualização do inglês sob tal perspectiva nos últimos anos.

Em uma primeira fase, Jenkins (1980) define que o foco dos estudos em ILF foi atribuído à forma da língua, pois ela constatou por meio de observações na comunicação de seus alunos dentro e fora da sala, e como a inteligibilidade mútua acontecia por ambas às partes, mesmo que os falantes não utilizassem modelos padronizados da língua. A partir dessas observações a autora começou a questionar a utilidade das normas de variedades nativas do idioma, as quais sustentavam a perspectiva do ILE, pois, nessa perspectiva, "os falantes não-nativos (os estrangeiros) teriam como objetivo de seu aprendizado aproximar-se ao máximo dos usuários nativos da língua" (JENKINS; COGO; DEWEY, 2011, p. 284 apud JORDÃO, 2014).

Em um segundo momento, a autora explicita que foi Seidlhofer (2008) quem identificou os problemas relacionados aos recursos do ILF, devido ao foco no entendimento e à possível descrição de uma nova variedade do idioma. A autora constatou que os usuários faziam uso da língua utilizando seus repertórios multilíngues, motivados pelo propósito comunicativo, e assim, propôs que os estudos do ILF se concentrassem nos processos dos usos variáveis feitos pelos falantes de ILF. Assim, o foco da forma mudou para a discussão sobre a variabilidade da língua, e, desse modo, a autora argumenta que embora a noção de Word Englishes seja de "modelos não nativos de inglês que são linguisticamente identificáveis, geograficamente definíveis" (KACHRU 1992, p. 66 apud JENKINS, 2000), a visão do ILF não é a mesma. Para a autora, na comunicação com o ILF, há fluidez e negociação de significado entre os interlocutores com repertório multilíngue variado que transcende as fronteiras, não podendo ser, portanto, variedades linguísticas delimitadas, ou relacionadas a territórios em específico. 
Por fim, na terceira fase de desenvolvimento de estudos sobre ILF, o foco se move para o inglês dentro de uma estrutura multilíngue. Tal inserção se dá pelo que a Jenkins (2000) chama de natureza emergente que o idioma possui, afirmando, inclusive, que o número de usuários de inglês nos últimos tempos continua a aumentar.

É perceptível que as pesquisas sobre o ILF são pautadas nos mais diversos contextos reais de uso desse idioma, contudo ainda são incipientes os estudos que abordem as implicações diretas desta perspectiva em sala de aula. Segundo Duboc (2019), ao relatar em seu estudo as diferentes fases do processo de publicações das pesquisas sobre o ILF, a própria pioneira dos estudos, Jenkins (2015), já demonstra preocupações em atualizar-se na perspectiva do ILF mediante os novos conceitos atribuídos e aprofundados sobre linguagem, mobilidade e translinguismo.

Portanto, nota-se que, embora haja estudos, ainda que recentes no Brasil, quando o assunto é o processo de ensino-aprendizagem ou a formação continuada para o preparo dos professores que já atuam com LI nas escolas, as informações aparecem em menor proporção. Trabalhos como o publicado por Salles e Gimenez (2010) já sinalizavam para a necessidade de uma reflexão sobre o status que a língua inglesa vinha recebendo, a partir de referências internacionais sobre o tema. El Kadri (2010) salienta que trabalhar na perspectiva do ILF enquanto professor não nativo pode ser visto como fator positivo, pois "ao invés de serem vistos e verem a si mesmos como falantes não nativos perenes e aprendizes de inglês como língua nativa, propensos a erros, eles podem ser usuários competentes do inglês como língua franca." (EL KADRI, 2010, p. 53).

Diante desses aspectos contextuais, discussões relativas ao trabalho e à formação docente sob a perspectiva do ILF atuando diretamente com os materiais didáticos que as escolas receberão para 0 trabalho com o NEM são fundamentais. A partir disso, será possível traçar os primeiros passos para unir a perspectiva de linguagem proposta pelo ILF relativa aos diversos contextos reais de comunicação do ILF, com as atividades de ensino e aprendizagem de língua voltada ao EM, a partir da nova proposta de 2017. O atendimento a essas demandas de formação também pode ser visto como uma forma de preparo aos educandos para o enfrentamento do processo de globalização. A própria Base contempla, nos objetivos sobre as práticas com LI no EM, que "abrem-se possibilidades de aproximação e integração desses estudantes com grupos multilíngues e multiculturais no mundo globalizado" (BRASIL, 2018, p. 485).

Nas escolas, a LI tradicionalmente tem se orientado pelo viés de língua estrangeira, inclusive no seu nome enquanto componente curricular "Língua Estrangeira Moderna - Inglês". A perspectiva do ILE, conforme definido anteriormente (JENKINS; COGO; DEWEY, 2011), trata basicamente, da busca pelos 
aprendizes da língua a alcançar a fluência "perfeita" e o mais próximo possível dos nativos do idioma, de modo atrelado a aspectos históricos e culturais relativos aos países onde o idioma é primeira língua.

Essa primazia da escrita é atribuída por diversos fatores, desde a falta de suporte para o trabalho com oralidade, como, por exemplo, turmas lotadas e que não atribuem significação ao idioma, como também por falta de proficiência dos próprios professores de LI para trabalhar com a oralidade. Nesse viés, os Parâmetros Curriculares Nacionais (PCN) também salientam que, no EM, deva-se privilegiar leitura, a interpretação e a língua escrita mais do que a língua falada, contudo o documento ressalta que é papel do professor abrir espaços para que múltiplas competências em outras esferas possam ser trabalhadas, inclusive quanto à língua oral (BRASIL, 2000).

Nesse sentido, Duboc (2019, p. 16) também destaca que tais encaminhamentos tendem a corroborar o fracasso do ensino em nosso sistema educacional, devido ao "ranço colonialista do inglês e a empreitada árdua de muitos brasileiros na busca idealizada do 'domínio' do idioma, calcado em preceitos como precisão, pureza e imitação do falante nativo". Ou seja, a busca por um distanciamento da perspectiva do ILE e uma aproximação ao ILF a partir das novas orientações para o ensino parecem constituir tentativas de superar as limitações impostas pela primeira visão.

Quando partimos para perspectiva proposta pela BNCC, que aborda o ILF, entendemos que, com base na definição de Jenkins (2009), torna-se possível ponderar que os diferentes sujeitos que fazem uso do inglês para comunicação são justamente os alunos que estão no processo de aprendizagem na escola. Eles possuem a língua portuguesa como primeira língua, mas em contextos do mundo global utilizarão a LI para comunicação com pessoas que também não possuem o inglês como primeira língua, visto que ela é a língua de caráter global. Nessa perspectiva, a BNCC, em seu texto introdutório da Área de Linguagens e suas Tecnologias, no que concerne à etapa do EM, ao abordar a LI, comenta justamente que é essa língua que abre possibilidades de aproximação e integração desses estudantes com grupos multilíngues e multiculturais no mundo globalizado (BRASIL, 2018).

Em seus estudos sobre a perspectiva do ILF, Duboc (2019) questiona acerca dos conteúdos propostos pela própria Base:

Como pode um documento acolher os usos criativos, híbridos e locais do inglês em seu status de língua franca se o próprio documento organiza, linear e hierarquicamente, temas, objetos de conhecimento e habilidades, com exemplos de conteúdos linguísticos fixos e estáveis? (DUBOC, 2019, p. 17)

Esse questionamento trata de uma análise do quadro de competências e habilidades proposto no $8^{\circ}$ ano do EF. A pergunta, porém, pode servir de subsídio à análise que aqui será detalhada. Na etapa que concerne ao EM na BNCC, não há uma apresentação sistematizada de conteúdos programados 
para serem trabalhos, nem sequências didáticas preparadas para desenvolver as habilidades propostas na Área de Linguagens, da qual a LI faz parte. Como esses conteúdos aparecerão, então, no EM e como - ILF entra em contraste com o ILE nos materiais didáticos, acabam sendo questões a serem solucionadas pelos professores em sala de aula com pouco ou nenhum direcionamento. Tal falta de direcionamento se dá também no ensino da oralidade, que ganha na Base um eixo específico e consequentemente maior foco.

\section{Ensino de oralidade}

Adotar a perspectiva do ILF acarreta em mudanças do ensino desse idioma que são, inclusive, apontados pela própria Base. $O$ documento define três principais mudanças, a primeira delas aborda a compreensão que pessoas ao redor do mundo todo fazem uso do inglês, e que isso possibilita questionar "a visão de que o único inglês correto - a ser ensinado - é aquele falado por estadunidenses ou britânicos" (BRASIL, 2018, p. 241). A segunda mudança relaciona-se com a ampliação das práticas de multiletramentos, inclusive no universo digital, no qual saber a LI potencializa as possibilidades de participação e circulação das diferentes semioses e linguagens. Por fim, a terceira implicação trata justamente da abordagem de ensino. $O$ documento salienta que cabe ao professor relativizar crenças, como, por exemplo, a de que existe um "inglês melhor" ou "nível de proficiência" ideal a ser alcançado. Além disso, ensinar inglês na perspectiva do ILF "exige do professor uma atitude de acolhimento e legitimação de diferentes formas de expressão na língua" (BRASIL, 2018, p. 242).

Essas três principais mudanças destacadas pela Base no ensino de inglês orientam os eixos organizadores do documento, sendo eles: Oralidade, Leitura, Escrita, Conhecimentos Linguísticos e Dimensão Intercultural (BRASIL, 2018). A oralidade historicamente tem sido relegada a um segundo plano na escola, em detrimento a um maior foco na escrita, fazendo com que o trabalho com as habilidades de compreensão e produção oral muitas vezes não fosse realizado, haja vista a inclusão dos recursos de áudio ter sido contemplada pelo Programa Nacional do Livro Didático (PNLD) somente a partir de 2015. "A inclusão do recurso multimídia passou a ser obrigatória e motivo de exclusão de toda a coleção, caso não seja aprovado" (MOTT-FERNANDEZ, 2014, p. 136). Apresentado esse panorama, o presente estudo enfoca no eixo oralidade, pois vê-se, aqui, a possibilidade de contribuir para os estudos nessa área.

Alguns documentos já introduziam a importância do trabalho com oralidade antes mesmo da publicação da BNCC. As próprias Orientações Curriculares para o Ensino Médio (OCEM), publicadas em 2006, trouxeram no tópico de língua estrangeira como novidade a inserção do desenvolvimento da 
comunicação oral. O documento enfatiza a necessidade de trabalho com oralidade e sugere dicas de trabalho com diálogos, textos simples de apresentação e orientações a turistas.

Contudo, é a BNCC que atribui uma relevância maior a esse ensino e destina um eixo exclusivo para o ensino de oralidade. Segundo o documento:

O eixo Oralidade envolve as práticas de linguagem em situações de uso oral da língua inglesa, com foco na compreensão (ou escuta) e na produção oral (ou fala), articuladas pela negociação na construção de significados partilhados pelos interlocutores e/ou participantes envolvidos, com ou sem contato face a face. (BRASIL, 2018, p. 243)

É notável que o ganho de um eixo específico para o ensino de oralidade representa um avanço para essa modalidade da língua. Contudo, quando chegamos à etapa do EM, esse eixo não é retomado e a LI passa a integrar a área de Linguagens e suas Tecnologias. O foco na oralidade não está propriamente descrito pela Base nessa etapa. Apenas uma breve discussão é realizada no texto de apresentação do componente afirmando que

Aspectos como precisão, padronização, erro, imitação e nível de proficiência ou domínio da língua são substituídos por noções mais abrangentes e relacionadas ao universo discursivo e passa-se, então, a levar em conta fatores como inteligibilidade, singularidade, variedade, criatividade/invenção e repertório. (BRASIL, 2018, p. 485).

Quando parte-se para uma análise das habilidades e competências a serem desenvolvidas pelo educando no EM, a carência de orientações para o ensino da oralidade de forma mais específica é ainda maior. Nessa etapa, há apenas uma habilidade que explicita a LI de forma mais particular:

"(EM13LGG403) Fazer uso do inglês como língua de comunicação global, levando em conta a multiplicidade e variedade de usos, usuários e funções dessa língua no mundo contemporâneo" (BRASIL, 2018, p. 494).

Destacar esse ponto não significa dizer que o professor não possa adequar o ensino de LI às demais habilidades que contemplam a área, contudo compreende-se que o EM é a etapa que resultaria em um aperfeiçoamento das práticas de oralidade iniciadas no EF. Portanto, ao voltar o olhar às práticas educacionais dessa etapa, observamos que, no EM, espera-se que educando faça uso do inglês como língua global, mas também trabalhe com uma análise crítica em relação à língua "permitindo, por exemplo, problematizar com maior criticidade os motivos pelos quais ela se tornou uma língua de uso global" (BRASIL, 2018, p. 485). Tal reflexo de ensino aparecerá na sala de aula e no trabalho do professor de LI, que usará de materiais didáticos e de apoio como auxílio para trabalhar com as práticas propostas pela Base. 
De modo a compreender como os materiais didáticos buscam contemplar o ensino do idioma no EM, sob a perspectiva do ILF, apresentamos uma breve análise de uma atividade envolvendo a prática de oralidade de um material didático que já começou a ser distribuído para as escolas-piloto do programa do NEM.

\section{Metodologia e análise}

Neste estudo, são analisadas duas unidades didáticas, cada uma de um livro didático distinto, da mesma editora, adotados para o EM, buscando estabelecer um contraste. A análise se pauta na perspectiva qualitativa, da qual, de acordo com Cohen, Manion e Morrison (2000), os resultados são derivados de interpretação. "O conhecimento não tem a pretensão positivista de ser normativo, porque é interpretativo, necessariamente inacabado, aberto a novas interpretações" (COHEN; MANION; MORRISON, 2000, p. 461). Tal dinâmica envolve os diferentes atores sociais no processo de compreensão e interpretação, inclusive o próprio pesquisador (LINCOLN; GUBA, 1985). Nesse sentido, há que se ressaltar que o primeiro autor deste estudo é professor de LI em escolas do NEM, de modo que a pesquisa apresenta grande importância para compreensão e aplicação pedagógica prática em sala de aula, sendo o material didático seu instrumento tanto de trabalho quanto de pesquisa.

Nas escolas da rede pública, o PNLD é o responsável por avaliar e disponibilizar obras didáticas, pedagógicas e literárias, entre outros materiais de apoio à prática educativa, de forma sistemática, regular e gratuita. Os materiais distribuídos pelo MEC para as escolas públicas de educação básica do país são escolhidos pelos professores das próprias escolas, desde que inscritos no PNLD e aprovados em avaliações pedagógicas coordenadas pelo Ministério da Educação e que conta com a participação de Comissões Técnicas específicas. Os livros selecionados para essa análise passaram pelo processo descrito acima e encontram-se em circulação em algumas escolas do estado de Santa Catarina.

Em vista disso, como forma de delimitar esse estudo, optamos por analisar essas edições justamente por estarem em circulação nas escolas estaduais de Santa Catarina, contexto de atuação profissional de um dos autores deste artigo. Sendo assim, buscaremos fazer um contraste entre dois livros: um livro que aborda a perspectiva do ILE, aprovado no PNLD 2018; e o outro, material encaminhado para escolha nas escolas piloto do NEM, que já aborda a perspectiva do ILF (2020). 0 primeiro foi distribuído na rede para ser utilizado nos anos de 2018, 2019 e 2020. Contudo, devido à pandemia da COVID-19 em 2020, houve atraso para envio dos materiais didáticos às escolas-piloto. Assim, esse material permanece em uso ainda em 2021. 
O primeiro livro em questão é o volume $2^{\circ}$ ano do EM intitulado Alive high (MENEZES et al., 2016) e foi publicado pela editora SM. O segundo livro, encaminhado a escolha para o NEM, é também da editora SM e foi publicado em 2020. Esse material é intitulado "Ser Protagonista - Projetos Integradores" (POUGY et al., 2020), ou seja, ele não é exclusivo de LI, afinal, uma das propostas da Base e do Programa é fazer com que as aprendizagens essenciais definidas na BNCC do EM sejam organizadas por áreas do conhecimento e que tenham por finalidade integrar dois ou mais componentes do currículo, para melhor compreender a complexa realidade e atuar nela (BRASIL, 2018).

É importante destacar que haverá livros específicos para LI que serão distribuídos às escolas em volumes únicos para os três anos do EM. Esses materiais específicos poderão ser utilizados como complementares aos projetos integradores, propostas de trabalhos integrados por área de conhecimento, e aos itinerários formativos optados pelo estudante. Contudo, no período de escrita deste artigo, julho de 2021, tais recursos ainda não estão disponíveis às escolas.

O livro Alive High traz, em sua apresentação na obra sobre a produção oral, que aspectos de pronúncia, tais como o reconhecimento de determinados sons, ritmos de palavras ou frases serão explorados por meio de repetição, tendo em vista dificuldades comuns aos falantes de português. Além disso, os autores afirmam que a proposta do material "não é formar falantes que se assemelham aos nativos, e o sotaque deve ser visto como uma característica identitária típica de qualquer falante de uma língua estrangeira" (MENEZES et al., 2016, p. 199). Isto é, o livro em questão visa a preparar os estudantes para compreenderem em serem compreendidos em LI, o que indica que o material, apesar de ter sido elaborado anteriormente à publicação da BNCC, já carrega consigo influências da perspectiva do ILF, embora isso não seja explicitado em sua apresentação.

O livro segue uma estrutura de oito unidades, as quais iniciam com Language in action visando a contextualizar 0 aluno sobre o que ele aprenderá na unidade. Após, apresenta uma atividade de vocabulário, uma de escuta, leitura e fala, um tópico gramatical, uma de produção e um encerramento para refletir sobre a aprendizagem. O livro, no geral, aborda a tecnologia como um tema geral de aprendizagem.

Já o livro mais recente, "Ser Protagonista", segue uma estrutura de seis unidades, sendo cada uma delas um projeto integrador que busca, em um primeiro momento, indagar aos alunos "Qual é o problema?" visando trabalhar com temas contemporâneos que sejam adequados a uma problemática atual. Após, divide-se em "Tramas e enredos" e "Traçando rotas", buscando solucionar o problema que foi elencado no início da unidade. Como o intuito é o trabalho integrado, cada projeto objetiva unir os componentes que fazem parte da Área de Linguagens e suas Tecnologias, assim, delimita um espaço em cada unidade para detalhar a "Trilha Educação Física", a "Trilha Língua Inglesa", a "Trilha Língua 
Portuguesa" e "Trilha Arte". Além disso, cada unidade/projeto apresenta uma atividade de "Mãos à obra" e "Boca no trombone", com objetivo de produzir e divulgar as produções realizadas pelo aluno naquela trilha. E por fim, apresenta a seção "Para avaliar", assim como tarefa semelhante no livro Alive High, para que 0 aluno possa analisar sua aprendizagem no final de cada projeto/unidade.

Diferente do livro Alive High, o "Ser Protagonista" não é exclusivo para $02^{\circ}$ ano, mas pode ser trabalhado ao longo de todo o EM, por isso aborda temas variados. Contudo, o nosso foco neste estudo será na Unidade/Projeto 3, intitulado "Midiaeducação". Tal escolha se dá, principalmente, por ele abordar o mesmo tema da Unidade 3 do livro Alive High, sendo o trabalho com o rádio, entrevistas e o gênero podcast. Assim, permite uma análise mais evidente nas atividades propostas sobre um mesmo tema, mas agora com perspectivas de Inglês diferentes.

\section{Análise das unidades}

A unidade 3 do livro Alive High apresenta um convite já no início da seção "Let's learn how to create a podcast" e, em seguida, fornece três objetivos da unidade: 1) Aprender como criar entrevistas. 2) Aprender como falar e descrever eventos passados. 3) Aprender como fazer perguntas. Em sequência, traz algumas imagens que abordam a criação do rádio e o desenvolvimento dele desde 1940 até 2014.

No livro Ser protagonista, a unidade 3 começa com uma situação problema "Como praticar a cidadania por meio das mídias?". Na parte "Tramas e Enredos", discute a questão de documentários produzidos por indígenas para, então, o projeto "Traçar a rota" e atribuir ao Inglês duas funções nesse projeto: 1) Conhecer, analisar e criar um podcast para compreender a produção midiática. 2) Conhecer a história da internet e refletir sobre ela para compreender a cultura contemporânea.

Após contextualizar o projeto, o livro Ser Protagonista, na Trilha de LI, assim como o Alive High, inicia a seção apresentando uma imagem com a história da comunicação. As imagens são diferentes em ambos os livros, enquanto no livro Alive High há imagens de pessoas ouvindo rádio em 1940 até um jovem ouvindo música em seus fones de ouvido em 2014, no livro Ser Protagonista, a imagem trazida é apenas dos aparelhos; há imagens desde uma vitrola até o símbolo dos streamings de músicas mais atuais. Ou seja, há de certa forma, uma espécie de atualização das formas de ouvir música no livro "Ser protagonista" ao apresentar, por exemplo, o Spotify. No livro Alive High, a representação mais contemporânea era um menino em seu fone com seu notebook.

Outro ponto parecido entre os dois livros é que no Alive High há um texto na atividade de foco na linguagem intitulado "A Brief History of Podcasting", extraído do website intitulado "MediaShift". 
Enquanto no livro Ser Protagonista, há um texto na atividade de Pre-Reading, intitulado "A Brief History of How We Communicate on the Internet", extraído de um blog intitulado "Seismic Blog".

Nesse viés, ambos os livros apresentam uma atividade de pré-listening e listening. No Livro Alive High, a sugestão é a música "Love is on the Radio", da banda inglesa McFly. Além disso, outra atividade contemplada também no livro Alive High é a escuta de uma entrevista da cantora Lady Gaga em uma cerimônia de apresentação do Academy Awards. Já no livro Ser Protagonista, a atividade consiste na escuta de um episódio "So Over The Moon" do programa de rádio "This American Life", que traz uma série de podcasts semanais.

O que é perceptível é que a música proposta no material do Alive High é de uma banda inglesa, de Londres, e a entrevista é de uma cantora estadunidense; enquanto o Podcast do material "Ser Protagonista" é de um programa dos Estados Unidos. Nesse caso, nota-se que há uma mudança em relação à presença das variedades do inglês nos recursos de áudio: enquanto no Alive High havia a presença da britânica (música da banda McFly) e norte-americana (a entrevista com a cantora Lady Gaga), no livro "Ser Protagonista" apresenta-se somente a norte-americana (podcast). Ou seja, podemos observar que o que permanece é o trabalho com materiais e atividades com duas variedades nativas de prestígio do inglês. A esse respeito, é importante destacar que a própria Base salienta a importância de entender, acolher e ensinar o inglês falado no mundo inteiro, justamente para desvincular-se da única visão de variante como sendo americana versus britânica.

Ou seja, trabalhar na perspectiva do ILF implicaria, nesse caso, apresentar também materiais de escuta que fizessem uso das diferentes variedades do inglês falado ao redor do mundo, justamente para que o aluno tivesse contato com usos diversos do idioma, característicos da sociedade contemporânea (BRASIL, 2018, p. 484), o que não pode ser observado nas atividades de ambos os volumes, os quais permanecem com exemplos de língua nas variedades norte-americana e britânica. Além disso, os dois livros não comtemplariam aspectos relativos à diversidade identitária dos falantes do inglês que a BNCC defende (BRASIL, 2018).

Pode-se observar também uma espécie de atualização do gênero textual utilizado nos exercícios de escuta o de produção oral, passando da entrevista, no livro Alive High, ao podcast, no livro "Ser Protagonista". No livro English Alive, a proposta de atividade consiste na elaboração de uma entrevista sobre o rádio. A atividade orienta o passo a passo de uma breve organização do que é necessário ter em uma entrevista e sugere que ela seja escrita em português para que, com auxílio de um tradutor online, seja traduzida para o Inglês. $O$ enunciado da atividade sugere que seja entrevistada uma pessoa mais velha sobre o rádio. Embora a entrevista seja um gênero que se aproxima da concepção discursiva mais oral (MARCUSCHI, 2010) do que escrita, o material não propõe uma atividade em que os alunos 
façam a gravação da entrevista, apenas sugere que ela pode ser gravada ou apenas escrita, caso 0 aluno deseje tomar notas na hora de fazer a transcrição, para ser publicada ou guardada no portfólio do educando.

Já na sugestão de produção oral do livro "Ser Protagonista" o desafio é criar um podcast. O livro fornece uma lista de orientações para que o podcast seja produzido e incentiva também que os tópicos para discussão, que serão utilizados na criação, sejam escritos em inglês. A orientação é que os alunos produzam um tipo de roteiro escrito do podcast, que, segundo o enunciado, sugere que os alunos se imaginem sendo partes de um comitê da NASA que ajudarão a incluir no "Gold Record" produções culturais da geração deles. Assim, sugere-se que essa gravação poderia ser enviada ao espaço sideral e ser imortalizada. A atividade orienta, e traz como dica ao professor, que, preferencialmente, seja produzido em LI, mas que os grupos que não se sentirem seguros, poderiam produzir em português.

Na nota ao professor dessa produção do podcast no livro Ser Protagonista, logo após sugerir que os alunos podem produzir em português, o material reconhece que embora o uso do português não seja proibido "é importante entender o papel da língua inglesa na difusão de conhecimentos e na cultura de compartilhamento, sobretudo por meio da internet" (POUGY et al., 2020, p. 95). Ao permitir que 0 aluno utilize 0 português, ainda que em momento inicial, 0 livro possibilita ao estudante 0 desenvolvimento de uma série de comportamentos como superar mal-entendidos e lidar com a insegurança, por exemplo (BRASIL, 2018).

O material orienta que os alunos gravem o podcast e comparem com os colegas e, após, compartilhem com a comunidade. Tal proposta está em consonância com o que a BNCC afirma ao abordar que no componente de LI no EM os alunos devem ser incentivados a "compartilhar informações e conhecimentos por meio da língua inglesa, como também agir e posicionar-se criticamente na sociedade, em âmbito local e global" (BRASIL, 2018, p. 485). A atividade "Writing Steps" orienta que 0 aluno organize informações prévias sobre seu entrevistado, prepare a sua primeira escrita, e, em seguida, troque ideias com seus colegas e, por fim, publique a versão escrita.

Diferente da proposta de produção oral do livro Alive High, o livro Ser Protagonista sugere que os alunos gravem suas produções, seus podcasts, em tópicos de 5 a 15 minutos, e mostrem as gravações aos colegas para comparar as recomendações feitas. Ambos os materiais sugerem que as atividades sejam publicadas. O livro Alive High sugere, além da cópia no portfólio do aluno, uma publicação em wikispaces, enquanto o livro "Ser Protagonista" orienta para que seja publicado, caso possível, para a comunidade e aberto a comentários.

O que é perceptível, portanto, é que apesar de o gênero entrevista ter a possibilidade ser aplicado, o material Alive High orienta apenas uma produção escrita dele, isso não significa que 0 
professor não possa aplicar a atividade de forma oral. Contudo, levando em consideração a aplicação de práticas, o material poderia orientar para uma prática mais autêntica de uso do gênero.

Outro ponto a ser destacado é que no livro "Ser Protagonista" há, no enunciado da atividade de listening, a seguinte sentença: "Don't focus on understanding every word of it, but on getting a big perspective of what is about". Nesse caso, o foco agora não está em entender cada palavra dita no texto, mas, sim, em abordar o sentido geral para que 0 aluno possa compreender e para que ocorra a comunicação. Nesse sentido, a própria base salienta, ao trabalhar com a perspectiva do ILF, que defende práticas situadas com vistas à inteligibilidade, em contraposição à padronização e ao erro (BRASIL, 2018).

É possível ponderar que as estratégias que 0 aluno utilizará para compreender esse áudio e depois no seu entendimento e na produção oral, são muito mais importantes do que o entendimento detalhado de cada palavra ou da repetição exata do modelo falante nativo. Tendo em vista as considerações de Jenkins (1980), ao desenvolver os estudos na perspectiva do ILF, observamos que 0 exercício de listening permite que haja uma comunicação na sua reprodução em seguida, sem utilizar de uma forma padronizada da língua, afinal, após ouvir a atividade 0 aluno fará usará suas próprias estratégias e seu próprio repertório para compreender e, consequentemente, comunicar-se em LI.

\section{Considerações finais}

Assim, ao final desse estudo, ressaltamos que foi possível discorrer sobre alguns estudos que já começaram a ser desenvolvidos na área do NEM e de LI, além de lançar um olhar ao percurso da definição do ILF proposto pelos teóricos e analisar duas unidades didáticas dos dois materiais distintos tratando da perspectiva do ILE e do ILF.

Diante da discussão apresentada, ponderamos que os primeiros passos para a mudança na implementação do NEM já estão sendo dados e, alguns estudos, ainda que inaugurais, já buscam contribuir para isso. São perceptíveis mudanças significativas nos materiais didáticos oferecidos, evidenciadas primeiramente pela adoção de um único volume integrado, deixando para trás as tradicionais coleções compostas por três livros.

Já no que tange pontualmente à perspectiva de ensino de LI, impactada pela publicação da BNCC, respaldada no ILF, pela análise aqui estabelecida, foi possível perceber que em ambos os materiais, "Alive High" (2016) e "Ser Protagonista" (2020), ainda prevalecem as variações de prestígio Americana e Britânica, as quais não devem ser excluídas, mas que a partir das indicações da Base, espera-se que os materiais passem a apresentar uma maior diversidade do idioma. 
Uma diferença relevante observada no livro "Ser Protagonista" é a presença de instruções diferentes em relação ao material do Alive High. No livro "Ser Protagonista", no que concerne aos exercícios de listening e speaking, há possibilidade de o aluno desenvolver suas habilidades com foco na comunicação, enfatizando sua relevância e não um uso idealizado do idioma e, também, abarca questões culturais na atividade, eixo que também ganha espaço na Base.

Além de atualizar-se tanto em relação ao formato esperado para o NEM, o livro mais recente apresenta uma contextualização por meio de imagens e utilização de gêneros textuais mais contemporâneos. Ponderamos, portanto, que isso provavelmente torna-se mais próximo da realidade dos alunos desta fase.

De modo geral, o que pode depreender-se das discussões aqui apresentadas é que as demandas decorrentes da implementação das propostas previstas tanto pela BNCC quanto pelo NEM devem se tornar centrais nos processos de formação de professores de LI, seja nos cursos de licenciatura, seja nas atividades de formação continuada. Assim sendo, estudos que se debrucem sobre estes aspectos podem contribuir com a compreensão sobre o que tais transformações implicam, bem como com a formulação destes processos formativos.

\section{Referências}

AMORIM, É. K. N.; GOMES, T. E. O ensino de língua inglesa e a BNCC: um estudo de caso. Reh- revista educação e humanidades, Amazonas, n. 2, p. 417-435, 22 jul. 2020. Disponível em: https://periodicos.ufam.edu.br/index.php/reh/article/view/7932/5649. Acesso em: 10 maio 2021.

BRASIL. Lei de Diretrizes e Bases da Educação Nacional, LDB. 9394/1996.

BRASIL. Lei da Política de Fomento à Implementação de Escolas de Ensino Médio em Tempo Integral. No 13.415 , de 16 de fevereiro de 2017.

BRASIL. Ministério da Educação. Base Nacional Comum Curricular. Brasília, 2018.

BRASIL, Ministério da Educação. Orientações Educacionais Complementares aos Parâmetros Curriculares Nacionais. Linguagens, Códigos e suas tecnologias. Disponível em: <http://portal.mec.gov.br/seb/arquivos/pdf/linguagens02.pdf> acesso em 04 mai. 2021.

BRASIL, Ministério da Educação, (2006). Orientações para o Ensino Médio OCEM Brasília, MEC.

BRASIL, Ministério da Educação, (2000). Parâmetros Curriculares Nacionais para o Ensino Médio. Brasilia, MEC.

BRASIL, Ministério da Educação, Secretaria de Educação Média e Tecnológica. Parâmetros curriculares nacionais, códigos e suas tecnologias. Língua estrangeira moderna. Brasília: MEC, 1999. pp 49-63. 
CAMARGO, G. Q.; SILVA, G. O inglês na educação básica brasileira: sabemos sobre ontem; e quanto ao amanhã?. Ensino e Tecnologia em Revista, Londrina, v. 1, n. 2, p. 258-271, 22 dez. 2017. DOI 10.3895/etr.v1n2.7500. Disponível em: https://periodicos.utfpr.edu.br/etr/article/view/7500. Acesso em: 3 maio 2021.

COHEN, L.; MANION, L.; MORRISON, K. Research Methods in Education. 5th ed. London: Routledge, 2000. 446p.

COSTA, M. O.; SILVA, L. A. Educação e democracia: Base Nacional Comum Curricular e novo ensino médio sob a ótica de entidades acadêmicas da área educacional. Revista Brasileira de Educação, Mato Grosso, v. 24, p. 1-23, 27 ago. 2019. Disponível em: https:/lanec.org.br/wpcontent/uploads/2020/04/Educacao-e-democracia-Novo-Ensino-Medio.pdf. Acesso em: 31 maio 2021.

DUBOC, A. P.M. Falando francamente: uma leitura bakhtiniana do conceito de "inglês como língua franca" no componente curricular língua inglesa da BNCC. Revista da Anpoll, Florianópolis, ano 2019, v. 1, n. 48, p. 10-22. Mai. 2019. DOI http://dx.doi.org/10.18309/anp.v1i48.1255. Disponível em: https://revistadaanpoll.emnuvens.com.br/revista/article/view/1255. Acesso em: 25 de abr. 2021

EL KADRI, M.S. Atitudes sobre o estatuto do inglês como língua franca em um curso de formação inicial de professores. 2010. 212 f. Dissertação (Mestrado em Estudos da Linguagem) - Universidade Estadual de Londrina, 2010. Disponível em: http://www.bibliotecadigital.uel.br/document/?code=vtls000153874. Acesso em: 6 jun. 2021.

FARIAS, P. F.; SILVA, L. "I'm gonna leave you with the backlash blues": uma análise acerca da concepção do ensino de língua inglesa na base nacional comum curricular sob o viés da pedagogia crítica. E-Curriculum, São Paulo, v. 18, p. 137-157, mar. 2020. DOI http://dx.doi.org/10.23925/18093876.2020v18i1p137-157.

Disponível em:https://revistas.pucsp.br/index.php/curriculum/article/view/44910/31733. Acesso em: 11 maio 2021.

FERREIRA, R. A.; RAMOS, L. O. L. O projeto da MP n 746: entre o discurso e o percurso de um novo ensino médio. Ensaio: avaliação e políticas públicas em educação, Rio de Janeiro, v. 26, n. 101, p. 1176 1196, 22 maio 2018. DOI https://doi.org/10.1590/S0104-40362018002601295. Disponível em: https://www.scielo.br/j/ensaio/a/tPGH7pYhJz8FGn9ZCNzKsCq/?format=pdf\&lang=pt. Acesso em: 5 jun. 20

JENKINS, J. Repositioning English and multilingualism in English as a Lingua Franca. De Gruyter. n. 2, p. 49-85. 2015. DOI 10.1515/eip-2015-0003. Disponível em: https://www.researchgate.net/publication/280945932_Repositioning_English_and_multilingualism_in_E nglish_as_a_Lingua_Franca. Acesso em: 13 maio 2021.

JORDÃO, Clarissa Menezes. ILA - ILF - ILE - ILG: Quem dá conta?. RBLA, Belo Horizonte, v. 14, n. 1, p. 13-40, 29 jan. 2014.23 Disponível https://www.scielo.br/j/rbla/a/VBC45fDYvxV5BXwvmLVDh4m/?lang=pt\&format=pdf. Acesso em: 23 out. 2021.

MARCUSCHI, L. A. Da fala para a escrita: Atividades de retextualização. 10. ed. São Paulo: Cortez Editora, 2010. 125 p. 
MARSON, M. Z. Ensino de língua inglesa no Brasil e decolonialidade: uma possível discussão com base na BNCC. Revista de estudos em educação. p. 8-22, 21 abr. 2021. Disponível em: https://www.praxia.ueg.br/index.php/reeduc/article/view/11455/8300. Acesso em: 28 maio 2021.

MENEZES, V.; BRAGA, J.; GOMES, R.; CARNEIRO, M.; RACILAN, M.; VELLOSO, M. Alive High. 2. ed. São Paulo: SM, 2016. 176 p.

MOTT-FERNANDEZ, C. A tessitura do gênero textual "manual do professor de coleções didáticas de língua inglesa" nas tramas do PNLD. 2014. 345 p. Tese (Doutorado em Estudos da Linguagem) Universidade Estadual de Londrina, Londrina, 2014.

PFEIFFER, C.; GRIGOLETTO, M. Reforma do Ensino Médio e BNCC - Divisões, Disputas e Interdições de Sentidos. Revista Investigações, Pernambuco, v. 31, n. 2, p. 9-25, 3 out. 2018. Disponível em: https://periodicos.ufpe.br/revistas/INV/article/view/237561. Acesso em: 12 jul. 2021.

POUGY, E.; VILELA, A.; ROSIGNOLI, C.; PIRES, J.; GRECO, L. Ser Protagonista: Projetos integradores. 1. ed. São Paulo: SM, 2020. 208 p.

ROCHA ALVES, P. C.; PIMENTEL SIQUEIRA, D. S. A perspectiva do inglês como língua franca como agente de decolonialidade no Ensino de Língua Inglesa. A Cor das Letras. v. 21, n. 2, p. 169-181, 2020. DOI: $\quad 10.13102 / c l . v 21$ i2.5072. Disponivel em: http://periodicos.uefs.br/index.php/acordasletras/article/view/169. Acesso em: 4 mai. 2021.

SANTANA, J. S.; KUPSKE, F. F. De língua estrangeira à língua franca e os paradoxos in-between: (tensionando) 0 ensino de língua inglesa à luz da BNCC. Revista X, Curitiba, v. 15, n. 5, p. 146-171, 5 out. 2020. DOI http://dx.doi.org/10.5380/rvx.v15i5.73397. Disponível em: https://revistas.ufpr.br/revistax/article/view/73397/41880. Acesso em: 22 jun. 2021.

SILVA, K. C. J. R. da; BOUTIN, A. C. Novo ensino médio e educação integral: contextos, conceitos e polêmicas sobre a reforma. Sistema de Información Científica Redalyc Red de Revistas Científicas, Universidade Federal de Santa Maria, v. 43, n. 31, p. 521-534, 2018. Disponível em: https://periodicos.ufsm.br/reveducacao/article/view/30458. Acesso em: 30 jun. 2021.

SÜSSEKIND, M. L. A BNCC e o "novo" Ensino Médio: reformas arrogantes, indolentes e malévolas. Retratos da escola, v. 13, n. 25, p. 91-107. 2019. DOI https://doi.org/10.22420/rde.v13i25.980. Disponível em: http://retratosdaescola.emnuvens.com.br/rde/article/view/980. Acesso em: 20 jun. 2021

Data de submissão: 23/08/2021. Data de aprovação: 28/10/2021. 